\title{
Molecular Complexation of Hederasaponin C with Cholesterol in Aqueous Isopropyl Alcohol
}

\author{
L. A. Yakovishin ${ }^{\mathrm{a}^{*}}$, V.I. Grishkovets ${ }^{\mathrm{b}}$, E.N. Korzh ${ }^{\mathrm{a}}$, \\ I. V. Golovchenko ${ }^{a}$, A. A. Nagirnyak ${ }^{a}$ \\ a Sevastopol State University, 33 University Str., Sevastopol, 299053, Russia \\ ${ }^{b}$ V.I. Vernadsky Crimean Federal University, 4 Vernadsky Ave., \\ Simferopol, 295007, Russia \\ *email: chemsevntu@rambler.ru
}

Abstract. The 1:1 molecular complex of ivy triterpene glycoside hederasaponin C (HedC) with cholesterol (Chol) was obtained in aqueous isopropyl alcohol. The stability constant of $(3.3 \pm 0.7) \cdot 10^{6}(\mathrm{~mol} / \mathrm{L})^{-1}$ was calculated for the complex. The complexation was studied by UV- and ATR IR-Fourier spectroscopy, and method of isomolar series. The hydrogen bonds and hydrophobic interactions are formed in the molecular complex.

Keywords: triterpene glycosides; hederasaponin C; cholesterol; molecular complex

Received: 06.08.2020. Accepted: 07.12.2020. Published:30.12.2020.

(c) Yakovishin L. A., Grishkovets V. I., Korzh E. N., Golovchenko I. V., Nagirnyak A. A., 2020

\section{Introduction}

Triterpene glycoside discovered in the most species of the ivy hederasaponin C (hederagenin genus Hedera L. (Araliaceae Juss.) [1]. 3-O- $\alpha$-L-rhamnopyranosyl- $(1 \rightarrow 2)-\quad \mathrm{HedC}$ is the dominant ivy saponin. HedC $O-\alpha$ - L-arabinopyranosyl-28-O- $\alpha-\quad$ was also founded in plants of various speL-rhamnopyranosyl-( $1 \rightarrow 4)-O-\beta$ - cies of Kalopanax, in Aralia elata, AcanD-glucopyranosyl-( $1 \rightarrow 6)-O-\beta-\mathrm{D}-\quad$ thopanax sieboldianus and Schefflera ocglucopyranoside, HedC; Fig. 1) was tophylla [1].
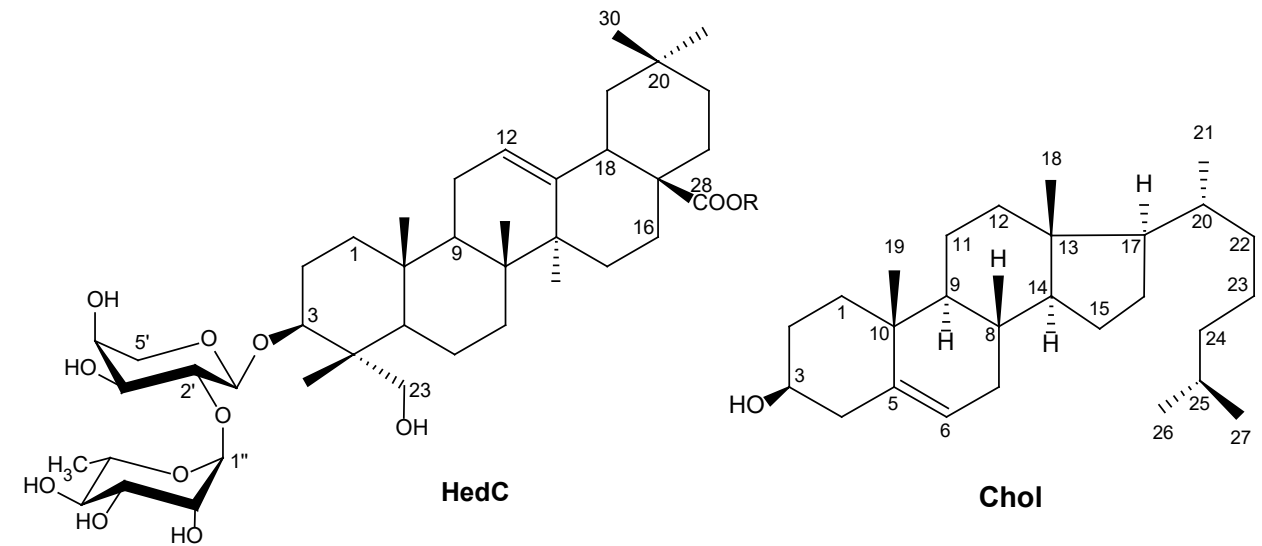

Fig. 1. Structures of HedC $\left(\mathrm{R}=\leftarrow \beta \mathrm{Glc}_{p}-(6 \leftarrow 1)-\beta \mathrm{Glc}_{p}-(4 \leftarrow 1)-\alpha \mathrm{Rha} \mathrm{p}_{p}\right)$ and Chol 
HedC is the component of antitussive drugs Prospan, Hedelix and other containing Hedera helix L. leaves [1]. A characteristic feature of triterpene glycosides is their ability to form molecular complexes with sterols [1-4]. The complexation of saponins with sterols is responsible for hemolytic, antitumor, ichthyotoxic, molluscicidal, antifungal, hypocholesterolaemic, and embryotoxic activity of triterpene glycosides $[1,2]$. On the other hand, it was reported that some triterpene glycosides do not form a molecular complex with cholesterol (Chol; Fig. 1) [3].

\section{Experimental}

HedC was preparatively isolated from leaves of Hedera canariensis Willd. (Araliaceae Juss.) by column chromatography on $\mathrm{SiO}_{2}$ and its structure was confirmed using chemical and physical methods [5].

The isomolar series were prepared by mixing $10^{-4} \mathrm{~mol} / \mathrm{L}$ solutions of HedC and Chol in $80 \%$ aqueous isopropyl alcohol (v/v) at $25^{\circ} \mathrm{C}$ for $40 \mathrm{~min}$ with continuous stirring. Spectroscopic analysis of isomolar series was performed on a LEKI SS2110UV spectrophotometer using a quartz cuvette $(l=1 \mathrm{~cm})$ at $25{ }^{\circ} \mathrm{C}$. Stability constant of the complex was calculated according to the A.K. Babko method based on isomolar curves $[4,6]$.

The complex of Chol with HedC was preparatively obtained by liquidphase method. For this purpose, $1 \mathrm{mmol}$ of the substances was mixed with $50 \mathrm{~mL}$ of $80 \%$ aqueous isopropyl alcohol (v/v). The obtained mixture was incubated at $50{ }^{\circ} \mathrm{C}$ for $1.5 \mathrm{~h}$ with continuous stirring. The organic solvent was removed under reduced pressure. Synthesized complex was analyzed by IR spectroscopy.
The interaction of HedC with Chol has been studied by spectrophotometric titration in aqueous ethanol [3] and isomolar series [4]. A preparation of molecular complex of Chol with HedC and bisdesmoside ivy triterpene glycoside hederacoside B mixture in aqueous ethanol and its analysis by planar chromatography [2] was previously reported.

To study the complexation of HedC with Chol in various media we examined their interaction in $80 \%$ aqueous isopropyl alcohol.
The IR spectra were recorded on the Simex FT-801 IR-Fourier spectrometer in the $4000-550 \mathrm{~cm}^{-1}$ region (spectral resolution $4 \mathrm{~cm}^{-1}$; 50 scans) using ATR accessory with diamante crystal plate.

IR spectrum of HedC $\left(v, \mathrm{~cm}^{-1}\right): 3333$ (OH), $2930(\mathrm{CH}), 2907(\mathrm{CH}), 2878(\mathrm{CH})$, $1734(\mathrm{C}=\mathrm{O}), 1624(\mathrm{C}=\mathrm{C}), 1451(\mathrm{CH}), 1433$ $(\mathrm{CH}), 1417(\mathrm{CH}), 1387(\mathrm{CH}), 1357(\mathrm{CH})$, $1342(\mathrm{CH}), 1319(\mathrm{CH}), 1260(\mathrm{CH}), 1230$ (CH), $1201(\mathrm{CH}), 1050(\mathrm{C}-\mathrm{O}-\mathrm{C}, \mathrm{C}-\mathrm{OH})$, 1024 (C-O-C, C-OH), 979 (=CH).

IR spectrum of Chol $\left(v, \mathrm{~cm}^{-1}\right): 3403$ $(\mathrm{OH}), 3337(\mathrm{OH}), 2929(\mathrm{CH}), 2899(\mathrm{CH})$, $2865(\mathrm{CH}), 2848(\mathrm{CH}), 1672(\mathrm{C}=\mathrm{C}), 1460$ $(\mathrm{CH}), 1434(\mathrm{CH}), 1377(\mathrm{CH}), 1364(\mathrm{CH})$, $1341(\mathrm{CH}), 1333(\mathrm{CH}), 1318(\mathrm{CH}), 1275$ $(\mathrm{CH}), 1268(\mathrm{CH}), 1253(\mathrm{CH}), 1234(\mathrm{CH})$, $1220(\mathrm{CH}), 1190(\mathrm{CH}), 1169(\mathrm{C}-\mathrm{OH}), 1132$ $(\mathrm{C}-\mathrm{OH}), 1106(\mathrm{C}-\mathrm{OH}), 1052(\mathrm{C}-\mathrm{OH})$, $1022(\mathrm{C}-\mathrm{OH}), 986(=\mathrm{CH}), 953(\mathrm{CH})$.

IR spectrum of the complex of $\mathrm{HedC}$ with Chol $\left(v, \mathrm{~cm}^{-1}\right)$ : $3316(\mathrm{OH}), 2930$ $(\mathrm{CH}), 2900(\mathrm{CH}), 2865(\mathrm{CH}), 1732(\mathrm{C}=\mathrm{O})$, $1670(\mathrm{C}=\mathrm{C}), 1625(\mathrm{C}=\mathrm{C}), 1458(\mathrm{CH})$, $1434(\mathrm{CH}), 1378(\mathrm{CH}), 1363(\mathrm{CH}), 1339$ 
$(\mathrm{CH}), 1316(\mathrm{CH}), 1261(\mathrm{CH}), 1230(\mathrm{CH})$, 1199 (CH), 1128 (C-O-C, C-OH), 1050
(C-O-C, C-OH), 1024 (C-O-C, C-OH), $983(=\mathrm{CH}), 958(\mathrm{CH})$.

\section{Results and discussion}

The composition of the complex of HedC with Chol was determined by the isomolar series method. This method gave a molar ratio $\approx 1.0$, which corresponded to a 1:1 complex (Fig. 2).

Such ratio was obtained for complex of $\mathrm{HedC}$ with Chol in $90 \%$ and $70 \%$ aqueous ethanol $[3,4]$, and for complexes of HedC with several drugs [7]. Stability constant of complex $(3.3 \pm 0.7)$. $\cdot 10^{6}(\mathrm{~mol} / \mathrm{L})^{-1}$ was calculated based on isomolar curves (A. K. Babko method) $[4,6]$. The stability constants of complex in aqueous ethanol were of the order $10^{-4}[3,4]$. Thus, the stability constant of complex formed in $80 \%$ aqueous isopropyl alcohol was greater than in aqueous ethanol.

As the HedC concentration increases (at constant Chol concentration), the optical density of their solutions increases (hyperchromic effect) (Fig. 3). The absorption maximum of the solutions decreases insignificantly (hypsochromic shift) from 237 to $230 \mathrm{~nm}$. Similar spectral changes were previously observed for molecular complexation of HedC with caffeine [7].

The complexation of HedC with Chol was studied by ATR FT-IR spectroscopy. The potential centers of intermolecular interactions in the molecules of HedC and $\mathrm{Chol}$ are $\mathrm{OH}$ groups. Indeed, upon the formation of complex in the IR spectra for the absorption bands of stretching vibrations of $\mathrm{O}-\mathrm{H}$ bonds in $\mathrm{Chol}$ are observed shifts from 3403 and $3337 \mathrm{~cm}^{-1}$ to $3316 \mathrm{~cm}^{-1}$, and in HedC - from 3333 to $3316 \mathrm{~cm}^{-1}$. This may indicate to formation of hydrogen bonds between HedC and Chol.

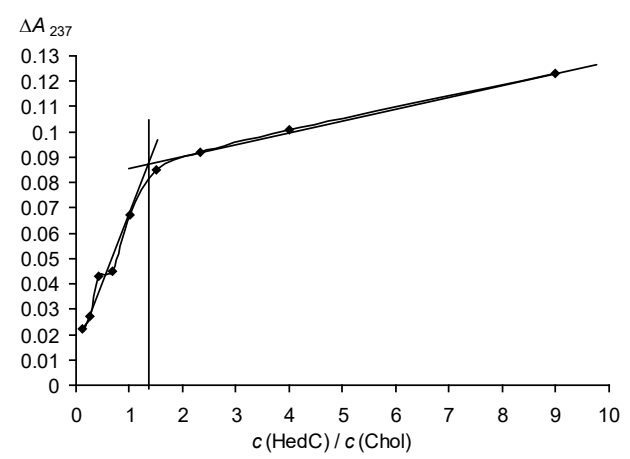

Fig. 2. Optical density change $\mathrm{D} A$ as a function of component ratio of isomolar series at $237 \mathrm{~nm}$

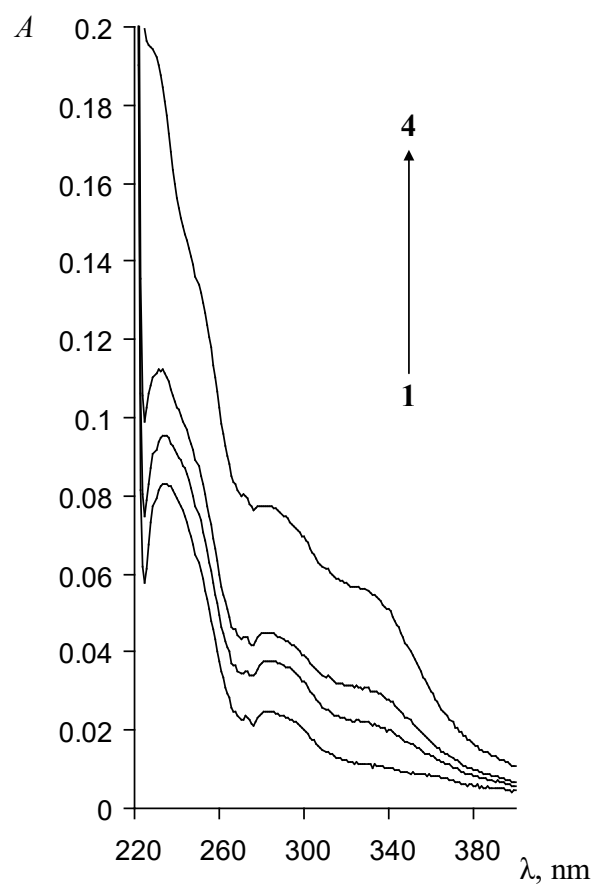

Fig. 3. UV spectra of Chol solutions $\left(0.50 \cdot 10^{-4} \mathrm{M}=\right.$ const $)$ with different concentrations of HedC: $0 \mathrm{M}$ (curve 1), $0.125 \cdot 10^{-4}$ (curve 2 ), $0.25 \cdot 10^{-4}$ (curve 3 ), $0.50 \cdot 10^{-4}$ (curve 4$)$ 
The complexation also causes changes in certain frequencies of absorption of $\mathrm{CH}$ bonds. These facts may indicate the presence of hydrophobic contacts between
Chol and HedC molecules in the molecular complex. The presence of hydrophobic interactions explains the high stability of triterpene glycosides molecular complexes [4].

\section{Conclusions}

The 1:1 molecular complex of HedC with Chol has been prepared for the first time in aqueous isopropyl alcohol. The presence of molecular complexation of Chol with HedC has been proved by UV- and ATR IR-Fourier spectroscopy.

Intermolecular interaction in the complex is carried out by hydrogen bonds formation and hydrophobic contacts. The results can be used to explain the mechanisms of the biological activity of triterpene glycosides.

\section{Acknowledgements}

This work was carried out within the framework of an internal grant of Sevastopol State University (identifier 30/06-31).

\section{References}

1. Hostettmann K, Marston A. Saponins. Cambrige: Cambrige University Press; 1995. $548 \mathrm{p}$.

2. Tschesche R, Wulff G. Konstitution und eigenschaften der saponine. Planta Medica. 1964;12(3):272-92. doi:10.1055/s-0028-1100180

3. Wojciechowski K, Orczyk M, Gutberlet T, Geue T. Complexation of phospholipids and cholesterol by triterpenic saponins in bulk and in monolayers. Biochim Biophys Acta Biomembr. 2016;1858(2):363-73.

doi:10.1016/j.bbamem.2015.12.001

4. Yakovishin LA, Grishkovets VI. Molecular complexes of ivy triterpene glycosides with cholesterol. Khimiya Rastitel'nogo Syr'ya. 2018;4:133-40. doi:10.14258/jcprm.2018043607

5. Grishkovets VI, Sidorov DYu, Yakovishin LA, Arnautov NN, Shashkov AS, Chirva VYa. Triterpene glycosides of Hedera canariensis I. Structures of glycosides L-A, L- $\mathrm{B}_{1}$, $\mathrm{L}-\mathrm{B}_{2}, \mathrm{~L}-\mathrm{C}, \mathrm{L}-\mathrm{D}, \mathrm{L}-\mathrm{E}_{1}, \mathrm{~L}-\mathrm{G}_{1}, \mathrm{~L}-\mathrm{G}_{2}, \mathrm{~L}-\mathrm{G}_{3}, \mathrm{~L}-\mathrm{G}_{4}, \mathrm{~L}-\mathrm{H}_{1}, \mathrm{~L}-\mathrm{H}_{2}$, and L-I from the leaves of Hedera canariensis. Chem Nat Compd. 1996;32(3):360-5. doi:10.1007/BF01372340

6. Babko AK. Phiziko-khimicheskii analiz kompleksnykh soedinenii v rastvorakh [Physico-chemical analysis of complex compounds in the solutions]. Kiev: Izd-vo AN USSR; 1955. 328 p. Russian.

7. Yakovishin LA, Grishkovets V.I. Ivy and licorice triterpene glycosides: promising molecular containers for some drugs and biomolecules. Stud Nat Prod Chem. 2018;55:351-83. doi:10.1016/B978-0-444-64068-0.00011-5 